\title{
Corrigendum
}

\section{T76. Baclofen as a Pharmacotherapy for the Treatment of Concurrent Alcohol and Nicotine Dependence: A Double-blind, Placebo-Controlled, Randomized Trial}

Mehdi Farokhnia, Steven M Edwards, Jared Bollinger, Jonathan Amodio, William H Zywiak, Jennifer W Tidey, Robert M Swift, George A Kenna and Lorenzo Leggio

Neuropsychopharmacology (20I5) 40, I560; doi:I0.1038/npp.20I5.29

Correction to: Neuropsychopharmacology (2014) 39, S291-S472; doi:10.1038/npp.2014.281
On page S340 of this abstract, the first sentence in the 'Results' section should be 'Baclofen-treated patients experienced significantly more increase in the percent days...' 